M. Syarief, Aplikasi Pestisida Berdasarkan Monitoring Dan Penggunaan Kelambu Kasa Plastik Pada Budidaya Bawang Merah

\title{
APLIKASI PESTISIDA BERDASARKAN MONITORING DAN PENGGUNAAN KELAMBU KASA PLASTIK PADA BUDIDAYA BAWANG MERAH
}

Oleh:

M. SYARIEF

\begin{abstract}
ABSTRAK
Tujuan penelitian ini untuk mengetahui pengaruh aplikasi pestisida berdasarkan monitoring dan penggunaan kelambu kasa plastil terhadap jenis hama dan penyakit yang menyerang tanaman bawang merah, intensitas serangan hama dan penyakit serta produksi bawang merah.

Penelitian ini telah dilaksanakan di Kebun Percobaan Politeknik Negeri Jember pada Desember 2010 sampai dengan Maret 2011, menggunakan Rancangan Acak Kelompok dengan pola faktorial, terdiri atas dua faktor yaitu Faktor A (aplikasi pestisida) terdiri atas dua level yaitu A0 (berdasarkan monitoring) dan A1 (terjadwal). Faktor B (penggunaan kelambu kasa plastik) terdiri atas dua level yaitu B0 (tanpa kelambu kasa plastik) dan B1 (menggunakan kelambu kasa plastik). Masing-masing kombinasi perlakuan diulang sebanyak 4 (empat) kali. Data pengamatan dianalisis menggunakan sidik ragam (Anova). Untuk membedakan antar perlakuan menggunakan Uji Beda Nyata Terkecil pada (BNT) pada taraf 5\%.

Kesimpulan penelitian ini sebagai berikut: jenis hama meliputi : Ulat Bawang (Spodoptera exigua) dan Trip (Thrip tabaci), penyakit meliputi: Becak ungu (Alternaria porri), Layu Fusarium (Fusarium oxyporum) dan Antraknose (Colletroticum gloeosporiodes), Intensitas serangan hama dipengaruhi oleh faktor penggunaan kelambu kasa plastik. Perlakuan B1 (menggunakan kelambu kasa plastik) menunjukkan intensitas serangan hama lebih rendah dibanding B0 (tanpa menggunakan kelambu kasa plastik), Terdapat interaksi pengaruh aplikasi pestisida dan penggunaan kelambu kasa plastik terhadap intensitas serangan penyakit. Pada umumnya AOB0 (aplikasi pestisida berdasarkan monitoring tanpa menggunakan kelambu kasa plastik) dan A1B0 (aplikasi pestisida terjadwal tanpa menggunakan kelambu kasa plastik) menunjukkan intensitas serangan penyakit lebih tinggi dibanding kombinasi perlakuan lainnya. Produksi bawang merah hanya dipengaruhi oleh faktor penggunaan kelambu kasa plastik. Perlakuan B1 (menggunakan kelambu kasa plastik) menunjukkan produksi yang lebih tinggi (10.58 ton per hektar) dibanding B0 (tanpa menggunakan kelambu kasa plastik) yaitu 6.75 ton per hektar.
\end{abstract}

Kata Kunci: monitoring, aplikasi pestisida, kelambu kasa plastik, intensitas serangan hama dan penyakit, produksi bawang merah 
M. Syarief, Aplikasi Pestisida Berdasarkan Monitoring Dan Penggunaan Kelambu Kasa Plastik Pada Budidaya Bawang Merah

\section{PENDAHULUAN}

Menurut konsep Pengendalian Hama Terpadu (PHT), monitoring hama dan penyakit merupakan cara untuk mengumpulkan data dan informasi tentang keadaan Organisme Pengganggu Tanaman (OPT), serangan dan musuh alaminya di lapangan, sekaligus merupakan pegangan bagi petani dalam mengelola lahan usahataninya dan pengambilan keputusan pengendalian. Pada cakupan yang lebih luas, monitoring hama dan penyakit diperlukan untuk mengumpulkan data yang akan dimanfaatkan sebagai bahan pelaporan, evaluasi, dan perencanaan. Selain itu, monitoring hama dan penyakit khusus (surveillance) menghasilkan data yang bermanfaat dalam pelaksanaan peramalan dan peningkatan kewaspadaan terhadap kemungkinan terjadinya serangan eksplosif (Anonim, 2005).

Masalah utama dalam budi daya bawang merah adalah serangan hama dan penyakit. Hamahama penting pada tanaman bawang merah antara lain ulat bawang (Spodoptera exigua exigua), Trips (Thrip tabaci)., penyakit yang biasa menyarang antara lain Alternaria porrii, penyakit Moler atau layu Fusarium (Fusarium oxyporum) dan penyakit yang disebabkan oleh Colletroticum gloesporioides (Adiyoga et.al., 2000; Ridlan and Rauf, 2003; Marwoto, 1993). Saat ini penggunaan jaring kelambu oleh petani bawang merah di kabupaten Probolinggo, dapat mencegah serangan hama ulat bawang dan menghemat kebutuhan pestisida. Jika dalam satu kali tanam kita menggunakan 95 liter pestisida, maka dengan menggunakan kelambu kasa plastik hanya menggunakan pestisida sekitar 10,5 liter. Secara ekonomis, penggunaan jaring kelambu juga menguntungkan. Meskipun biaya investasi jaring kelambu mencapai Rp. 21,5 juta per hektar, namun jaring kelambu tersebut dapat digunakan hingga delapan kali (Anonim, 2005). Mengingat dampak negatif yang mungkin timbul akibat penggunaan pestisida yang tidak bijaksana, maka perlu dilakukan penelitian tentang pengaruh monitoring hama dan penyakit serta penggunaan jaring kelambu dalam budidaya sayuran terhadap intensitas serangan hama dan penyakit dan produksi bawang merah. Hal ini perlu dilakukan penelitian karena pada umumnya petani yang menggunakan kelambu tanpa melakukan monitoring hama dan penyakit; dan penyakit tanaman bawang merah tidak terhalang oleh penggunaan kelambu, terutama penyakit-penyakit soil borne, air borne.
Tujuan penelitian ini adalah:

(1) Mengetahui jenis hama dan penyakit yang menyerang tanaman bawang merah

(2) Mengetahui pengaruh monitoring hama dan penyakit terhadap intensitas serangan hama dan penyakit serta produksi.

(3) Mengetahui pengaruh penggunaan kelambu kasa plastik terhadap intensitas serangan hama dan penyakit serta produksi.

(4) Mengetahui interaksi pengaruh monitoring hama dan penyakit dan penggunaan kelambu kasa plastik terhadap intensitas serangan hama dan penyakit serta produksi.

Manfaat hasil penelitian ini dapat digunakan sebagai teknologi inovatif dalam budidaya bawang merah.

\section{METODOLOGI PENELITIAN}

Penelitian ini dilaksanakan pada bulan Desember 2010 sampai dengan Maret 2011 di Kebun Percobaan Politeknik Negeri Jember. Bahan penelitian meliputi: bibit bawang merah varietas Philipine, insektisida, fungisida, perekat, pupuk NPK. Alat penelitian meliputi: jaring kelambu warna putih, bambu, Knapsack Sprayer, gelas ukur $100 \mathrm{ml}$, gelas ukur $5 \mathrm{ml}$, corong plastik, timba, roll meter, cangkul, rafia.

Penelitian menggunakan Rancangan Acak Kelompok dengan pola faktorial, terdiri atas dua faktor yaitu Faktor A (teknik aplikasi pestisida) terdiri atas dua level yaitu A0 (aplikasi pestisida berdasarkan monitoring) dan A1 (aplikasi pestisida terjadwal). Faktor B (penggunaan kelambu kasa plastik) terdiri atas dua level yaitu B0 (tanpa kelambu kasa plastik) dan B1 (menggunakan kelambu kasa plastik). Masing-masing kombinasi perlakuan diulang sebanyak 4 (empat) kali. Data pengamatan dianalisis menggunakan sidik ragam (Anova). Untuk membedakan antar perlakuan menggunakan Uji Beda Nyata Terkecil pada (BNT) pada taraf 5\%. Pengamatan, meliputi: Jenis hama dan penyakit yang menyerang tanaman bawang merah, Intensitas serangan hama dan penyakit dan produksi (berat basah) per hektar.

Intensitas serangan hama dan penyakit menggunakan rumus Townsend dan Hueberger sebagai berikut:

$$
\mathrm{P}=\frac{\sum(\mathrm{n} \times \mathrm{v})}{\mathrm{N} \mathrm{X} \mathrm{Z}}
$$


M.Syarief, Aplikasi Pestisida Berdasarkan Monitoring Dan Penggunaan Kelambu Kasa Plastik Pada Budidaya Bawang Merah

$$
\begin{gathered}
\mathrm{P}=\text { tingkat kerusakan tanaman (dalam persen) } \\
\mathrm{n}=\text { jumlah daun rusak dalam skala tertentu } \\
\mathrm{V}=\text { nilai skala kerusakan } \\
\mathrm{N}=\text { jumlah daun yang diamati per rumpun } \\
\mathrm{Z}=\text { nilai skala kerusakan tertinggi }
\end{gathered}
$$

Nilai skala kerusakan yaitu:

$0=$ tidak ada kerusakan pada daun

$1=$ kerusakan daun $<25 \%$

$2=$ kerusakan daun antara $25-<50 \%$

$3=$ kerusakan daun antara $50-75 \%$

$4=$ kerusakan daun $>75 \%$

Untuk intensitas serangan hama hama dan penyakit yang menyebabkan kerusakan mutlak menggunakan rumus:

persen)

$$
\mathrm{P}=\frac{\mathrm{a}}{\mathrm{a}+\mathrm{b}}
$$

$\mathrm{P}=$ tingkat kerusakan tanaman (dalam

$\mathrm{a}=$ jumlah tanaman terserang

$\mathrm{b}=$ jumlah tanaman sehat

\section{HASIL DAN PEMBAHASAN}

hasil penelitian berjudul: "Aplikasi pestisida berdasarkan monitoring dan penggunaan kelambu kasa plastik pada budidaya bawang merah " disajikan dalam tabel-tabel sebagai berikut:

Tabel 1. Hama Yang Menyerang Tanaman Bawang Merah di Areal Penelitian

\begin{tabular}{|c|c|c|c|c|c|c|c|c|c|c|c|c|c|c|}
\hline \multirow{3}{*}{$\begin{array}{l}\text { Sumber } \\
\text { Keragaman }\end{array}$} & \multicolumn{12}{|c|}{ F Hit } & \multirow{3}{*}{$\begin{array}{r}\mathrm{F} \\
5 \% \\
3.86\end{array}$} & \multirow{3}{*}{$\begin{array}{c}\text { Tabel } \\
1 \% \\
6.99\end{array}$} \\
\hline & \multicolumn{2}{|c|}{$3 \mathrm{MST}$} & \multicolumn{2}{|c|}{$4 \mathrm{MST}$} & \multicolumn{2}{|c|}{$5 \mathrm{MST}$} & \multicolumn{2}{|c|}{$6 \mathrm{MST}$} & \multicolumn{2}{|c|}{$7 \mathrm{MST}$} & \multicolumn{2}{|c|}{$8 \mathrm{MST}$} & & \\
\hline & 3.20 & ns & 3.08 & $\mathrm{~ns}$ & 3.03 & ns & 2.36 & $\mathrm{~ns}$ & 2.94 & ns & 2.57 & ns & & \\
\hline Perlakuan & 6.99 & $*$ & 6.73 & $*$ & 6.77 & $*$ & 6.02 & $*$ & 6.36 & $*$ & 6.14 & $*$ & 3.86 & 6.99 \\
\hline A & 0.00 & $\mathrm{~ns}$ & 0.00 & $\mathrm{~ns}$ & 0.00 & ns & 0.00 & $\mathrm{~ns}$ & 0.03 & $\mathrm{~ns}$ & 0.02 & $\mathrm{~ns}$ & 5.12 & 10.56 \\
\hline B & 20.97 & $* *$ & 20.18 & ** & 20.31 & $* *$ & 18.05 & $* *$ & 19.05 & $* *$ & 18.40 & $* *$ & 5.12 & 10.56 \\
\hline AXB & 0.00 & ns & 0.00 & ns & 0.00 & ns & 0.00 & ns & 0.01 & $\mathrm{~ns}$ & 0.00 & ns & 5.12 & 10.56 \\
\hline
\end{tabular}

\begin{tabular}{|l|l|l|}
\hline No & \multicolumn{1}{|c|}{ Nama Daerah } & \multicolumn{1}{|c|}{ Jenis } \\
\hline 1 & Ulat Bawang & S. exigua \\
\hline 2 & Trips & T. tabaci \\
\hline
\end{tabular}

Tabel 2. Penyakit Yang Menyerang Tanaman Bawang Merah di Areal Penelitian

\begin{tabular}{|c|c|c|c|c|c|c|c|c|c|c|c|c|}
\hline \multirow{3}{*}{$\begin{array}{l}\text { Perlakuan } \\
\text { B0 } \\
\end{array}$} & \multicolumn{12}{|c|}{ Intensitas Serangan } \\
\hline & \multicolumn{2}{|c|}{$3 \mathrm{MST}$} & \multicolumn{2}{|c|}{$4 \mathrm{MST}$} & \multicolumn{2}{|c|}{$5 \mathrm{MST}$} & \multicolumn{2}{|c|}{$6 \mathrm{MST}$} & \multicolumn{2}{|c|}{$7 \mathrm{MST}$} & \multicolumn{2}{|c|}{$8 \mathrm{MST}$} \\
\hline & 28.44 & $\mathrm{~b}$ & 28.85 & $\mathrm{~b}$ & 29.03 & $\mathrm{~b}$ & 28.95 & $\mathrm{~b}$ & 28.91 & $\mathrm{~b}$ & 28.63 & $\mathrm{~b}$ \\
\hline B1 & 16.43 & $\mathrm{a}$ & 16.61 & $\mathrm{a}$ & 16.43 & $\mathrm{a}$ & 16.79 & $a$ & 16.78 & $\mathrm{a}$ & 16.61 & $\mathrm{a}$ \\
\hline BNT 5\% & 1.05 & & 1.09 & & 1.12 & & 1.14 & & 1.11 & & 1.12 & \\
\hline
\end{tabular}

\begin{tabular}{|l|l|l|}
\hline No & Nama Penyakit & Spesies \\
\hline 1 & Becak ungu & A. porrii \\
\hline 2 & Layu Fusarium & F. oxyporum \\
\hline 3 & Antraknose & $\begin{array}{l}\text { C. gloesporioides } \\
\text {, , , }\end{array}$ \\
\hline
\end{tabular}

Tabel 3. Sidik Ragam Intensitas Serangan Hama pada 3, 4, 5, 6, 7 dan 8 Minggu Setelah Tanam (MST)

Keterangan: $\mathrm{ns}=$ berbeda tidak nyata $*$ = berbeda nyata $* *=$ berbeda sangat nyata

Tabel 4 Pengaruh kelambu kasa plastik terhadap intensitas serangan hama (data ditransformasi ke Vx +0.5 ) 
Berdasarkan sidik ragam, terdapat pengaruh sangat nyata dari penggunaan kelambu kasa plastik terhadap intensitas serangan hama pada 3, 4, 5, 6, 7 dan 8 Minggu Setelah Tanam (MST). Pada umumnya penggunaan kelambu kasa plastik menunjukkan intensitas serangan hama yang lebih rendah dibanding tanpa menggunakan jaring kelambu, hal ini disebabkan fungsi kelambu kasa plastik dapat menghalangi masuknya hama sejak bibit bawang merah ditanam.

Tabel 5. Sidik ragam intensitas serangan penyakit pada 3, 4, 5, 6 dan 7 MST

\begin{tabular}{|c|c|c|c|c|c|c|c|c|c|c|c|c|c|c|}
\hline \multirow{2}{*}{$\begin{array}{l}\text { Sumber } \\
\text { Keragaman }\end{array}$} & \multicolumn{12}{|c|}{ F Hit } & \multirow{2}{*}{$\begin{array}{r}\mathrm{F} \\
5 \% \\
\end{array}$} & Tabel \\
\hline & \multicolumn{2}{|c|}{$3 \mathrm{MST}$} & \multicolumn{2}{|c|}{$4 \mathrm{MST}$} & \multicolumn{2}{|c|}{$5 \mathrm{MST}$} & \multicolumn{2}{|c|}{$6 \mathrm{MST}$} & \multicolumn{2}{|c|}{$7 \mathrm{MST}$} & \multicolumn{2}{|c|}{$8 \mathrm{MST}$} & & $1 \%$ \\
\hline Kelompok & 2.65 & ns & 1.77 & $\mathrm{~ns}$ & 2.19 & $\mathrm{~ns}$ & 0.71 & ns & 3.67 & ns & 2.73 & $\mathrm{~ns}$ & 3.86 & 6.99 \\
\hline Perlakuan & 9.98 & $* *$ & 9.64 & $* *$ & 10.40 & $* *$ & 5.46 & $*$ & 6.98 & $*$ & 6.06 & $*$ & 3.86 & 6.99 \\
\hline A & 8.46 & $*$ & 0.05 & ns & 0.02 & ns & 0.47 & $\mathrm{~ns}$ & 3.82 & ns & 4.56 & ns & 5.12 & 10.56 \\
\hline B & 14.15 & $* *$ & 2.09 & ns & 2.68 & ns & 2.32 & ns & 8.22 & $*$ & 11.61 & $* *$ & 5.12 & 10.56 \\
\hline AXB & 7.33 & $*$ & 26.78 & $* *$ & 28.50 & $* *$ & 13.60 & $* *$ & 8.89 & $*$ & 2.02 & ns & 5.12 & 10.56 \\
\hline
\end{tabular}

Keterangan: $\mathrm{ns}=$ berbeda tidak nyata $*$ berbeda nyata $* *=$ berbeda sangat nyata

Tabel 6. Interaksi Pengaruh Monitoring dan kelambu kasa plastik terhadap intensitas serangan penyakit (data ditransformasi ke $\mathrm{Vx}+0.5$ )

\begin{tabular}{|c|c|c|c|c|c|c|c|c|c|c|}
\hline \multirow{2}{*}{$\begin{array}{l}\text { Kombinasi } \\
\text { Perlakuan }\end{array}$} & \multicolumn{10}{|c|}{ Intensitas Serangan Penyakit $(\mathrm{Vx}+0.5)$} \\
\hline & \multicolumn{2}{|c|}{$3 \mathrm{MST}$} & \multicolumn{2}{|c|}{$4 \mathrm{MST}$} & \multicolumn{2}{|c|}{$5 \mathrm{MST}$} & \multicolumn{2}{|c|}{$6 \mathrm{MST}$} & \multicolumn{2}{|c|}{$7 \mathrm{MST}$} \\
\hline A0B0 & 2.48 & $\mathrm{~b}$ & 3.03 & $\mathrm{~b}$ & 3.03 & $\mathrm{~b}$ & 3.11 & $\mathrm{~b}$ & 3.23 & $\mathrm{~b}$ \\
\hline $\mathrm{AOB} 1$ & 0.96 & $\mathrm{a}$ & 0.96 & $\mathrm{a}$ & 1.03 & $\mathrm{a}$ & 1.03 & $\mathrm{a}$ & 1.44 & $\mathrm{a}$ \\
\hline $\mathrm{A} 1 \mathrm{~B} 0$ & 0.96 & $\mathrm{a}$ & 3.03 & $\mathrm{~b}$ & 3.03 & $\mathrm{~b}$ & 2.43 & $\mathrm{~b}$ & 2.11 & $\mathrm{~b}$ \\
\hline A1B1 & 1.12 & $\mathrm{a}$ & 1.12 & $\mathrm{a}$ & 1.12 & $\mathrm{a}$ & 1.11 & $\mathrm{a}$ & 1.22 & $\mathrm{a}$ \\
\hline BNT 5\% & 0.56 & & 0.89 & & 0.84 & & 1.05 & & 0.82 & \\
\hline
\end{tabular}

Keterangan: angka rata-rata yang diikuti huruf yang sama dalam satu kolommenunjukkan berbeda tidak nyata menurut uji BNT pada taraf 5\%.

Tabel 7. Pengaruh kelambu kasa plastik terhadap intensitas serangan penyakit (data ditransformasi ke $V x+0.5$ )

\begin{tabular}{|l|cc|}
\hline Perlakuan & Intensitas Serangan Penyakit & \\
\hline B0 & 4.48 & b \\
\hline B1 & 2.50 & a \\
\hline BNT 5\% & 0.86 & \\
\hline
\end{tabular}

Keterangan: angka rata-rata yang diikuti huruf yang sama dalam satu kolommenunjukkan tidak berbeda nyata menurut uji BNT pada taraf 5\%.

Berdasarkan sidik ragam intensitas serangan hama pada 3, 4, 5, 6 dan 7 MST, terdapat interaksi pengaruh teknik aplikasi pestisida dan penggunaan kelambu kasa plastik terhadap intensitas serangan
Penyakit. Pada 8 MST hanya faktor penggunaan kelambu kasa plastik yang berbeda sangat nyata. Hal ini dapat disebabkan oleh pertumbuhan bawang merah yang menjelang panen, sehingga intensitas serangan 
M.Syarief, Aplikasi Pestisida Berdasarkan Monitoring Dan Penggunaan Kelambu Kasa Plastik Pada Budidaya Bawang Merah

penyakit di areal penelitian tidak mempengaruhi teknik pengendalian. Pada umumnya kombinasi perlakuan aplikasi pestisida berdasarkan monitoring maupun terjadwal tanpa menggunakan kelambu kasa plastik menunjukkan intensitas serangan penyakit yang lebih tinggi, demikian halnya pada 8 MST, perlakuan tanpa menggunakan kelambu kasa plastik menunjukkan ratarata intensitas serangan penyakit lebih tinggi pula hal ini dapat disebabkan kelambu kasa plastik tidak dapat menghambat menghambat curah hujan yang sangat mendukung perkembangan penyakit.

Tabel 7. Sidik Ragam Produksi Bawang Merah per Hektar

\begin{tabular}{|l|cc|c|c|}
\hline \multirow{2}{*}{$\begin{array}{l}\text { Sumber } \\
\text { Keragaman }\end{array}$} & \multirow{2}{*}{$\mathrm{F}$} & \multicolumn{2}{|c|}{$\mathrm{F}$} \\
\cline { 3 - 5 } & Hitung & & $5 \%$ & $1 \%$ \\
\hline Kelompok & 0.95 & $\mathrm{~ns}$ & 3.86 & 6.99 \\
\hline Perlakuan & 4.22 & $*$ & 3.86 & 6.99 \\
\hline A & 0.04 & $\mathrm{~ns}$ & 5.12 & 10.56 \\
\hline B & 11.61 & $* *$ & 5.12 & 10.56 \\
\hline AXB & 1.00 & $\mathrm{~ns}$ & 5.12 & 10.56 \\
\hline
\end{tabular}

Keterangan: $\mathrm{ns}=$ berbeda tidak nyata $*=$ berbeda nyata $* *=$ berbeda sangat nyata

Tabel 8. Pengaruh jaring kelambu terhadap produksi bawang merah per hektar (ton)

\begin{tabular}{|l|cc|}
\hline Perlakuan & \multicolumn{2}{|c|}{ Produksi (ton) } \\
\hline B0 & 6.75 & a \\
\hline B1 & 10.58 & b \\
\hline BNT 5\% & 1.79 \\
\hline
\end{tabular}

Keterangan: angka rata-rata yang diikuti huruf yang sama dalam satu kolom menunjukkan berbeda tidak nyata menurut uji BNT pada taraf $5 \%$.

Berdasarkan sidik ragam, penggunaan kelambu kasa plastik berbeda sangat nyata terhadap produksi bawang merah per hektar. Hal ini dapat dijelaskan bahwa penggunaan kelambu kasa plastik dapat menekan populasi telur dan larva serta intensitas kerusakan tanaman dan secara tidak langsung mampu meningkatkan jumlah anakan, tinggi tanaman, jumlah daun dan umbi bawang mera (Soetiarso, 2010).

\section{KESIMPULAN DAN SARAN}

Kesimpulan

Berdasarkan hasil penelitian dapat disimpulkan sebagai berikut:

1. Hama yang menyerang tanaman bawang merah meliputi : Ulat Bawang ( $S$ exigua) dan Trip (T. tabaci), penyakit meliputi: Becak ungu (A. porrii), Layu Fusarium (F. oxyporum) dan Antraknose (C. gloeosporiodes)

2. Intensitas serangan hama pada bawang merah hanya dipengaruhi oleh faktor penggunaan kelambu kasa plastik. Perlakuan B1 (menggunakan kelambu kasa plastik) menunjukkan intensitas serangan hama yang lebih rendah dibanding B0 (tanpa menggunakan kelambu kasa plastik)

3. Terdapat interaksi pengaruh teknik aplikasi pestisida dan penggunaan kelambu kasa plastik terhadap intensitas serangan penyakit bawang merah. Pada umumnya AOB0 (teknik aplikasi pestisida berdasarkan monitoring tanpa menggunakan kelambu kasa plastik) dan A1B0 (teknik aplikasi pestisida terjadwal tanpa menggunakan kelambu kasa plastik) menunjukkan intensitas serangan penyakit lebih tinggi dibanding kombinasi perlakuan lainnya.

4. Produksi bawang merah hanya dipengaruhi oleh faktor penggunaan kelambu kasa plastik. Perlakuan B1 (menggunakan kelambu kasa plastik) menunjukkan produksi yang lebih tinggi (10.58 ton per hektar) dibanding B0 (tanpa menggunakan kelambu kasa plastik) yaitu 6.75 ton per hektar.

Saran

Disarankan untuk melakukan penelitian lanjutan tentang pengaruh teknik aplikasi pestisida berdasarkan monitoring dan penggunaan kelambu kasa plastik pada budidaya bawang merah pada musim kemarau. 


\section{DAFTAR PUSTAKA}

Anonim, 2005. Penerapan Pengendalian Hama Terpadu Bawang Merah di Provinsi Jawa Timur, Dinas Pertanian Provinsi Jawa Timur, Balai Proteksi Tanaman Pangan dan Hortikultura, Jawa Timur.

Anonim, 2005. Pengendalian Organisme Pengganggu Tanaman Bawang Merah dengan Menggunakan Jaring Kelambu. Dinas Pertanian Tanaman pangan, Kehutanan dan perkebunan Kabupaten Probolinggo. Jawa Timur.

Adiyoga, W., T.K. Moekasan, T.S. Uhan, E. Soenaryo dan Hendarsih, 2000. Present Status of Pests and Deseases management on food and vegetable crops and its future development. Lap. PEI dan PT. PCI

Marwoto, B. 1993. Pengendalian Nematode Spiral (Helycotylenchus retusus) pada tanaman bawang merah secara hayati: Pengaruh berbagai cendawan tular tanah terhadap perkembangan $H$. retusus pada tanaman bawang merah. Bul. Penel. Hort. 15:(1):9 - 15.

Ridlan, P. and A. Rauf, 2003. Linomyza huidobrensis leaf miner: developing effective pest management strategies for Indonesian and Australia Review Report of leafminer project.

Soetiarso,T.A., 2010. Teknologi Inovatif Bawang Merah dan Pengembangannya, Balai Penelitian Tanaman Sayuran, Lembang Bandung. 